\title{
PCP4: a regulator of aldosterone synthesis in human adrenocortical tissues
}

\author{
Saulo J A Felizola, Yasuhiro Nakamura, Yoshikiyo Ono', Kanako Kitamura, \\ Kumi Kikuchi', Yoshiaki Onodera, Kazue Ise, Kei Takase ${ }^{2}$, Akira Sugawara ${ }^{3}$, \\ Namita Hattangady ${ }^{4}$, William E Rainey ${ }^{4}$, Fumitoshi Satoh ${ }^{1}$ and Hironobu Sasano \\ Department of Pathology, Tohoku University Graduate School of Medicine, 2-1 Seiryo-machi, Aoba-ku, Sendai, \\ Miyagi 980-8575, Japan \\ ${ }^{1}$ Division of Nephrology, Endocrinology and Vascular Medicine, Tohoku University Hospital, Sendai, Japan \\ Departments of ${ }^{2}$ Diagnostic Radiology ${ }^{3}$ Molecular Endocrinology, Tohoku University Graduate School of Medicine, \\ 2-1 Seiryo-machi, Aoba-ku, Sendai, Miyagi 980-8575, Japan \\ ${ }^{4}$ Department of Physiology and Medicine, University of Michigan, Ann Arbor, Michigan, USA
}

\author{
Correspondence \\ should be addressed \\ to $Y$ Nakamura \\ Email \\ yasu-naka@ \\ patholo2.med.tohoku.ac.jp
}

\begin{abstract}
Purkinje cell protein 4 (PCP4) is a calmodulin (CaM)-binding protein that accelerates calcium association and dissociation with CaM. It has been previously detected in aldosteroneproducing adenomas (APA), but details on its expression and function in adrenocortical tissues have remained unknown. Therefore, we performed the immunohistochemical analysis of PCP4 in the following tissues: normal adrenal (NA; $n=15)$, APA $(n=15)$, cortisolproducing adenomas $(n=15)$, and idiopathic hyperaldosteronism cases (IHA; $n=5)$. APA samples $(n=45)$ were also submitted to quantitative RT-PCR of PCP4, CYP11B1, and CYP11B2, as well as DNA sequencing for KCNJ5 mutations. Transient transfection analysis using PCP4 siRNA was also performed in H295R adrenocortical carcinoma cells, following ELISA analysis, and CYP11B2 luciferase assays were also performed after PCP4 vector transfection in order to study the regulation of PCP4 protein expression. In our findings, PCP4 immunoreactivity was predominantly detected in APA and in the zona glomerulosa of NA and IHA. In APA, the mRNA levels of $P C P 4$ were significantly correlated with those of CYP11B2 $(P<0.0001)$ and were significantly higher in cases with KCNJ5 mutation than WT $(P=0.005)$. Following PCP4 vector transfection, CYP11B2 luciferase reporter activity was significantly higher than controls in the presence of angiotensin-II. Knockdown of PCP4 resulted in a significant decrease in CYP11B2 mRNA levels $(P=0.012)$ and aldosterone production $(P=0.011)$. Our results indicate that PCP4 is a regulator of aldosterone production in normal, hyperplastic, and neoplastic human adrenocortical cells.
\end{abstract}

\author{
Key Words \\ - Purkinje cell protein 4 (PCP4) \\ - adrenal cortex \\ - aldosterone \\ - calmodulin (CaM) \\ - CYP11B2
}

Journal of Molecular

Endocrinology

(2014) 52, 159-167

\section{Introduction}

Purkinje cell protein 4 (PCP4), also known as PEP-19, is a $7.6 \mathrm{kDa}$ protein with an IQ-motif that binds to calmodulin (CaM) (Wei et al. 2011). PCP4 is abundant in Purkinje cells of the cerebellum, and plays an important role in synaptic plasticity (Sangameswaran et al. 1989, Wei et al. 2011). PCP4-null mice were reported to exhibit impaired locomotor learning and markedly altered synaptic plasticity in cerebellar Purkinje neurons (Wei et al. 2011). 
PCP4 accelerates both the association and dissociation of calcium $\left(\mathrm{Ca}^{2+}\right)$ with $\mathrm{CaM}$, which is postulated to influence the activity of CaM-dependent enzymes, especially CaM kinase II (Putkey et al. 2003, Kleerekoper \& Putkey 2009, Wei et al. 2011). It has been also reported that PCP4 can prevent cellular degeneration and apoptosis, as neuroprotection in the CNS (Erhardt et al. 2000, Johanson et al. 2000, Slemmon et al. 2000). Recently, PCP4 expression has been reported to be up-regulated in adrenocortical aldosterone-producing adenoma (APA), compared with APA-adjacent adrenal gland (Wang et al. 2011). However, details of its expression within the adrenocortical layers, and its possible functions in normal or pathological adrenocortical tissues, have remained unclear.

Therefore, in this study, we evaluated PCP4 immunoreactivity in normal and neoplastic adrenocortical tissues, explored a possible function using the H295R adrenocortical carcinoma cell line, and correlated its expression with that of adrenal steroidogenic enzymes. In addition, we also evaluated the correlation between the status of PCP4 and KCNJ5 somatic mutations in APA (Choi et al. 2011, Zennaro \& Jeunemaitre 2011).

\section{Materials and methods}

\section{Human adrenal tissues}

The research protocols were approved by the Ethics Committee at Tohoku University Graduate School of Medicine (Sendai, Japan). All patients read and signed informed consent documents regarding the diagnostic and scientific use of tissue samples and clinical data.

For immunohistochemical analysis (IHC), 15 nonpathological adrenal glands (normal adrenal (NA)), five idiopathic hyperaldosteronism (IHA), and 30 adrenocortical tumor specimens (15 APA and 15 cortisolproducing adenomas (CPA)) were retrieved from the surgical pathology files of Tohoku University Hospital (Sendai, Japan). NA tissues were obtained from nephrectomy cases due to renal carcinoma, and were subsequently evaluated to confirm the absence of neoplastic invasion, necrosis, or other histopathological abnormalities.

APA and IHA patients in our study underwent adrenal vein sampling at Tohoku University Hospital, following the previously reported protocol (Satoh et al. 2007). The IHA patients were relatively young, and unilateral adrenalectomy was performed to lower circulating aldosterone levels, in order to further prevent future organ damage (Sukor et al. 2009, Nakamura et al. 2011).
Therefore, all IHA patients in this study agreed to surgical treatment. The histopathological diagnosis of IHA was based on the presence of hyperplastic zona glomerulosa (ZG) with a marked 3 $\beta$-HSD immunostaining, in contrast to the adjacent adrenal cortex of APA, which expresses very low levels of $3 \beta-H S D$ in the ZG (Nakamura et al. 2011).

For quantitative RT-PCR analysis (qPCR) and DNA sequencing, 45 APA samples were obtained from Tohoku University Hospital, with clinical data retrieved from the respective clinical records. All APA patients were treated with spironolactone before surgery.

\section{Immunohistochemical analysis}

Rabbit polyclonal antibody of human PCP4 was purchased from Sigma-Aldrich and used at 1:2000 dilution. IHC technique was carried as previously reported (Felizola et al. $2013 a, b)$.

After completely reviewing the slides, relative immunoreactivity of PCP4 in each zone of the adrenocortex as well as in tumor specimens was evaluated by a modified $H$-score of nuclei and the counting of positive cytoplasm, carried out by examining three high-power fields and counting 1000 cells (Lai et al. 2007). Regarding cytoplasmic immunoreactivity, a semiquantitative evaluation was used, and a scoring of 0-4 corresponded to 0-1, 1-25, 25-50, 50-75, and 75-100\%, as described (Hui et al. 2009). The nuclear and cytoplasmic evaluations were independently and blindly carried out by two of the authors (S J A F and $\mathrm{K} \mathrm{K}$ ) and the mean values were used for analysis.

\section{RNA isolation and qPCR}

RNA isolation with subsequent cDNA production and qPCR technique were performed as previously reported (Felizola et al. 2013a,b, 2014). The primer sequences used in our study were PCP4 forward, 5'-TGA CAT GGA TGC ACC AG- $3^{\prime}$ and reverse, $5^{\prime}$-GTG TGG ATT GTG TGT GG-3'; CYP11B1 forward, 5'-CCC AGC ACA AAT GGA ACT CCC GA-3' and reverse, 5'-CCG CTT AAT GAC TCT GAC AGT CTG CG-3'; CYP11B2 forward, 5'-TCC AGG TGT GTT CAG TAG TTC C-3' and reverse, 5'-GAA GCC ATC TCT GAG GTC TGT G-3'; and RPL13A forward, 5'-CCT GGA GGA GAA GAG GAA AG-3' and reverse, 5'-TTG AGG ACC TCT GTG TAT TT- $3^{\prime}$. The cDNA produced from a human brain specimen was used as a positive control in the PCP4 and RPL13A qPCR experiments, while the cDNA from H295R adrenocortical carcinoma cells was used as a positive control for CYP11B1 and CYP11B2.

Published by Bioscientifica Ltd. 
The relative gene expression was calculated as previously reported (Felizola et al. 2014). For the analysis of cell experiments data, the relative gene expression was calculated by the $\Delta \Delta C \mathrm{t}$ method as reported (Nogueira et al. 2007). RPL13A was used as an endogenous control gene.

\section{Cell culture}

Human adrenocortical carcinoma cells H295R (Bird et al. 1995) were cultured in DMEM/Eagle's F12 medium (Invitrogen) and supplemented with 10\% Cosmic Calf Serum (CCS; Hyclone Laboratories, Inc., Nampa, ID, USA), $1 \%$ penicillin/streptomycin (Invitrogen), and $0.01 \%$ gentamycin (Sigma-Aldrich). The cells were maintained in a $37^{\circ} \mathrm{C}$ humidified atmosphere $\left(5 \% \mathrm{CO}_{2}\right)$.

\section{H295R cell line assays and following qPCR analysis}

H295R cells were transferred to 12-well dishes in groups of 600000 cells/well, and maintained at the conditions described. After $24 \mathrm{~h}$ passage, DMEM/Eagle's F12 medium supplemented with $0.1 \%$ CCS and, after $48 \mathrm{~h}$, DMEM/ Eagle's F12 media containing angiotensin-II (Ang-II; Tocris, Bristol, UK; $10 \mathrm{nM}$ ), and forskolin (Tocris; $10 \mu \mathrm{M}$ ) were added to different groups of cells, each group comprising three wells. A basal group, to which no drug was added, was used as the control. RNA was extracted at 3, 6, 12, and $24 \mathrm{~h}$ time points (RNeasy Mini Kit, Qiagen). All the cell experiments were independently conducted in triplicate, with cells raised at different times.

\section{PCP4 transient siRNA knockdown and ELISA}

Human PCP4 MISSION siRNA (Sigma-Aldrich) and MISSION siRNA Universal Negative Control 1 (Sigma-Aldrich) were transfected into $\mathrm{H} 295 \mathrm{R}$ cells at $40 \mathrm{ng} / \mu \mathrm{l}$ concentration using a Nucleofector-4D electroporator machine (Lonza, Koln, Germany). After transfection, the cells were transferred to 12-well dishes in groups of 600000 cells/well, and after $48 \mathrm{~h}$ RNA and protein were harvested from one set of cells. The remaining cells were either treated with Ang-II (10 nM) or vehicle from this point. After $60 \mathrm{~h}$ from transfection, RNA was collected from i) cells transfected with PCP4 siRNA plus vehicle; ii) cells transfected with PCP4 siRNA plus Ang-II; iii) cells transfected with negative control (NC) siRNA plus vehicle; and iv) cells transfected with NC siRNA plus Ang-II respectively. In addition, cell media were collected $96 \mathrm{~h}$ after transfection and were submitted to ELISA analysis of aldosterone and cortisol with ALPCO ELISA Kits
(ALPCO Diagnosis, Salem, NH, USA). These ELISA data were adjusted by protein concentration at these time points. All the experiments were independently performed in triplicate.

\section{PCP4 transient DNA transfection and luciferase assays}

MCF7 breast cancer cells were transfected with the plasmid produced in Escherichia coli using the following DNA primers: forward, 5'-GGG GCT AGC ATG AGT GAG CGA CAA GGT GCT G-3' and reverse, 5'-CGC AAG CTT CAC TAG GAC TGA GAC CCA GCC-3'. The pcDNA3.1(-) vector (Invitrogen) was used as a backbone for the PCP4 plasmid. NC MCF7 cells were transfected with empty vector. Protein was collected and western blotting performed in order to confirm and evaluate the transient transfection.

After confirmation of plasmid activity, H295R cells were grown to $80 \%$ confluence in 24-multiwell plates, and transiently transfected with $200 \mathrm{ng}-1521 /+2$-luc harboring the $5^{\prime}$-flanking region of CYP11B2 (CYP11B2-LUC), and 300 ng pcDNA of PCP4 or control pcDNA using Lipofectamine LTX and Plus Reagent (Invitrogen) for $24 \mathrm{~h}$. The media were changed to DMEM supplemented with $1 \%$ stripped FBS, and the cells were incubated either with or without Ang-II (100 nM) for $6 \mathrm{~h}$. Following incubation, cell extracts were prepared using Glo Lysis Buffer (Promega). Luciferase activity was measured using Bright-Glo Reagents (Promega), and protein concentration was measured using protein assay kit (Bio-Rad). Data were normalized by protein concentration.

\section{Western blotting analysis}

Both H295R and MCF7 cell lines were submitted to total protein extraction with the M-PER mammalian protein extraction reagents (Thermo Scientific, Rockford, IL, USA) after the addition of Halt protease inhibitor (Thermo Scientific). Semi-dry immunoblotting was carried out using a nitrocellulose membrane after SDS-page electrophoresis. The immunoblot membrane was incubated overnight with rabbit polyclonal anti-human PCP4 antibody (Sigma-Aldrich) in a 1:400 dilution or mouse monoclonal anti- $\beta$-actin antibody (Sigma-Aldrich). Chemiluminescence was performed using the Amersham ECL Prime western blotting detection reagent (GE Healthcare Life Sciences, Little Chalfont, Bucks, UK) following the incubation with an anti-rabbit or anti-mouse second-antibody for $1 \mathrm{~h}$. The immunoreactive bands were analyzed through dark-chamber photography

Published by Bioscientifica Ltd. 
with a Fujifilm luminescent image analyzer model LAS-1000CH (Fujifilm, Tokyo, Japan), and quantification performed with integrated analysis software.

\section{DNA sequencing and mutations in $K C N J 5$}

APA specimens $(n=45)$ were submitted to PCR using a KCNJ5 primer (forward, 5'-CGA CCA AGA GTG GAT TCC TT- $3^{\prime}$ and reverse, $5^{\prime}$-AGG GTC TCC GCT CTC TTC TT-3') with annealing temperature at $65^{\circ} \mathrm{C}$. After cooling, all samples were submitted to electrophoresis in agarose gel $0.1 \%$ and DNA purification with a QIAquick gel extraction kit (Qiagen). Analysis of the purified DNA was carried out with a ABI PRISM 310 Genetic Analyzer (Applied Biosystems), and mutations at the G151R and L168R regions of the KCNJ5 gene were analyzed as described (Choi et al. 2011).

\section{Statistical analysis}

Data from the IHC of NAC and IHA samples were evaluated in the three groups (ZG, zona fasciculata (ZF), and zona reticularis (ZR)) using Mann-Whitney multiple comparison tests with the significance level set to $\alpha=0.05$. The Bonferroni inequality was used to correct multiple comparisons, with $0.05 / 3=0.0167$ resulting in $P<0.0167$ as the statistically significant value. The statistical difference between the cortical layers of NAC and IHA, as well as between APA and CPA samples, was evaluated using Mann-Whitney $U$ tests, and $P<0.05$ was considered statistically significant.

Data from the qPCR of human tissues were evaluated using regression analysis and/or Mann-Whitney $U$ tests. A correlation coefficient of $R>0.3$ and/or $P<0.05$ was considered significant. The statistical analysis of patient gender and its correlation to KCNJ5 mutations was assessed by contingency table, and a $\chi^{2}$ value of $P<0.05$ was considered significant. The data from cell experiments in vitro were evaluated using either ANOVA post-hoc tests or $t$-tests, with the significance level set to $\alpha=0.05$, and the Bonferroni inequality was used to correct multiple comparisons when applicable.

\section{Results}

\section{Immunohistochemical analysis}

Results of $H$-scores of nuclei and positive cytoplasm of NA and IHA are shown in Fig. 1A and B respectively, and adrenocortical tumors in Fig. $1 \mathrm{C}$ and D. PCP4 immunoreactivity was detected in the nuclei of the $Z G$, the $Z F$, and the ZR cells of NA (Fig. 1A and Supplementary Figs 1, 2 and 3, see section on supplementary data given at the end of this article) and IHA (Fig. 1B and Supplementary Figs 4, 5 and 6), with a significantly higher nuclear immunoreactivity in the $Z G$ compared with the other two
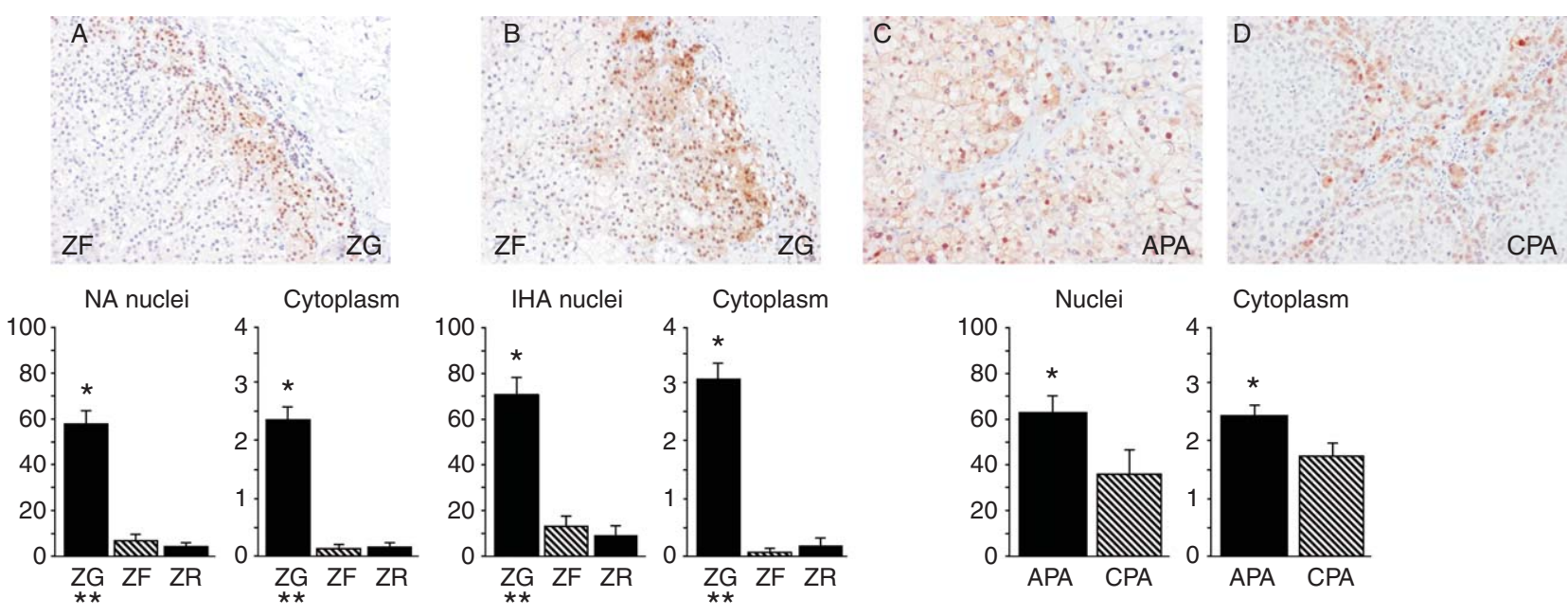

\section{Figure 1}

Immunohistochemistry of PCP4. Nuclei were evaluated by modified $\mathrm{H}$-score and cytoplasm by semi-quantitative scoring. (A) Normal adrenal (NA), (B) idiopathic aldosteronism (IHA). Results on $\mathrm{H}$-score (nuclei) and semiquantitative evaluation (cytoplasm) are below the respective photographs and indicate the zona glomerulosa (ZG), zona fasciculata (ZF), and the zona reticularis (ZR). Significantly higher nuclear and cytoplasmic Printed in Great Britain
() 2014 Society for Endocrinology immunostaining was detected in the ZG of IHA than the ZG of NA (**P<0.05), but no statistical difference was observed when comparing the other layers. (C) Aldosterone-producing adenoma and (D) cortisolproducing adenoma. S.D.s are indicated as error bars in the graphics, $\star P<0.001$. A full colour version of this figure is available via http://dx.doi. org/10.1530/JME-13-0248.

Published by Bioscientifica Ltd 
A

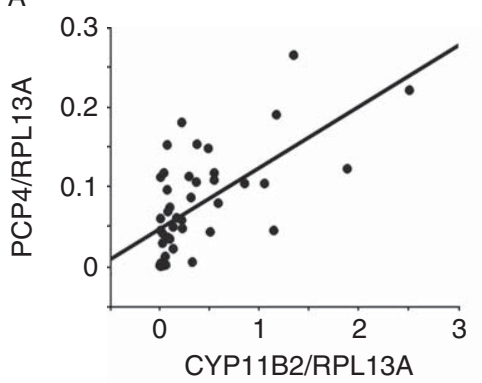

D

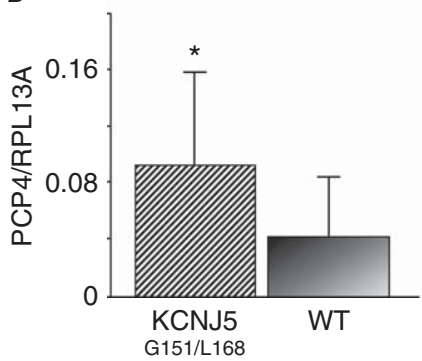

B

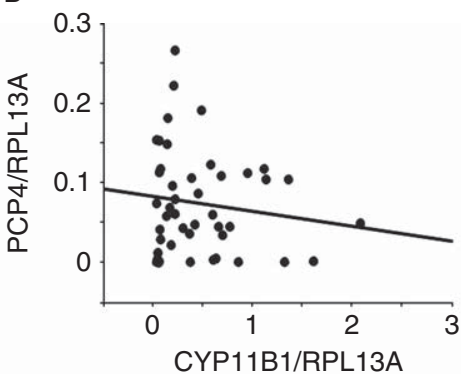

$\mathrm{E}$

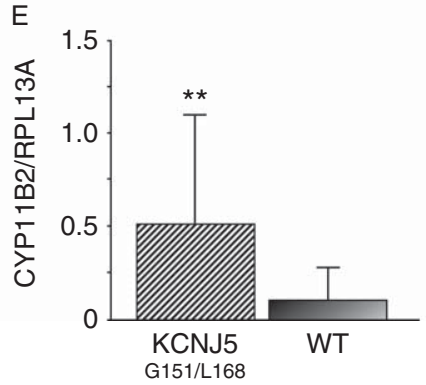

C

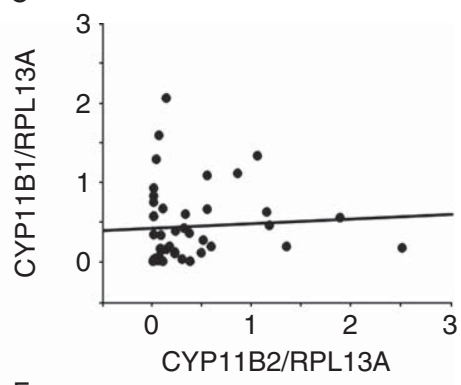

$\mathrm{F}$

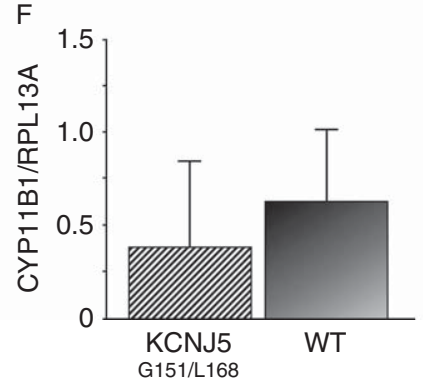

\section{Figure 2}

Real-time quantitative PCR (qPCR) analysis of PCP4, CYP11B2, and CYP11B1, and DNA sequencing of KCNJ5 in 45 APA samples. (A) A significant statistical correlation was detected between $P C P 4$ and $C Y P 11 B 2$ relative mRNA levels $(P<0.0001 ; R>0.6)$. (B) No statistical significance was observed between PCP4 and CYP11B1. (C) No statistical significance was detected between CYP11B1 and CYP11B2 mRNA levels. (D) PCP4 levels were significantly higher in $K C N J 5$ mutated samples than WT ( $\left.{ }^{*} P=0.005\right)$. (E) CYP11B2 were also higher in $K C N J 5$ mutated specimens $(* * P<0.005)$. (F) No statistical relationship was detected between CYP11B1 and KCNJ5 mutations.
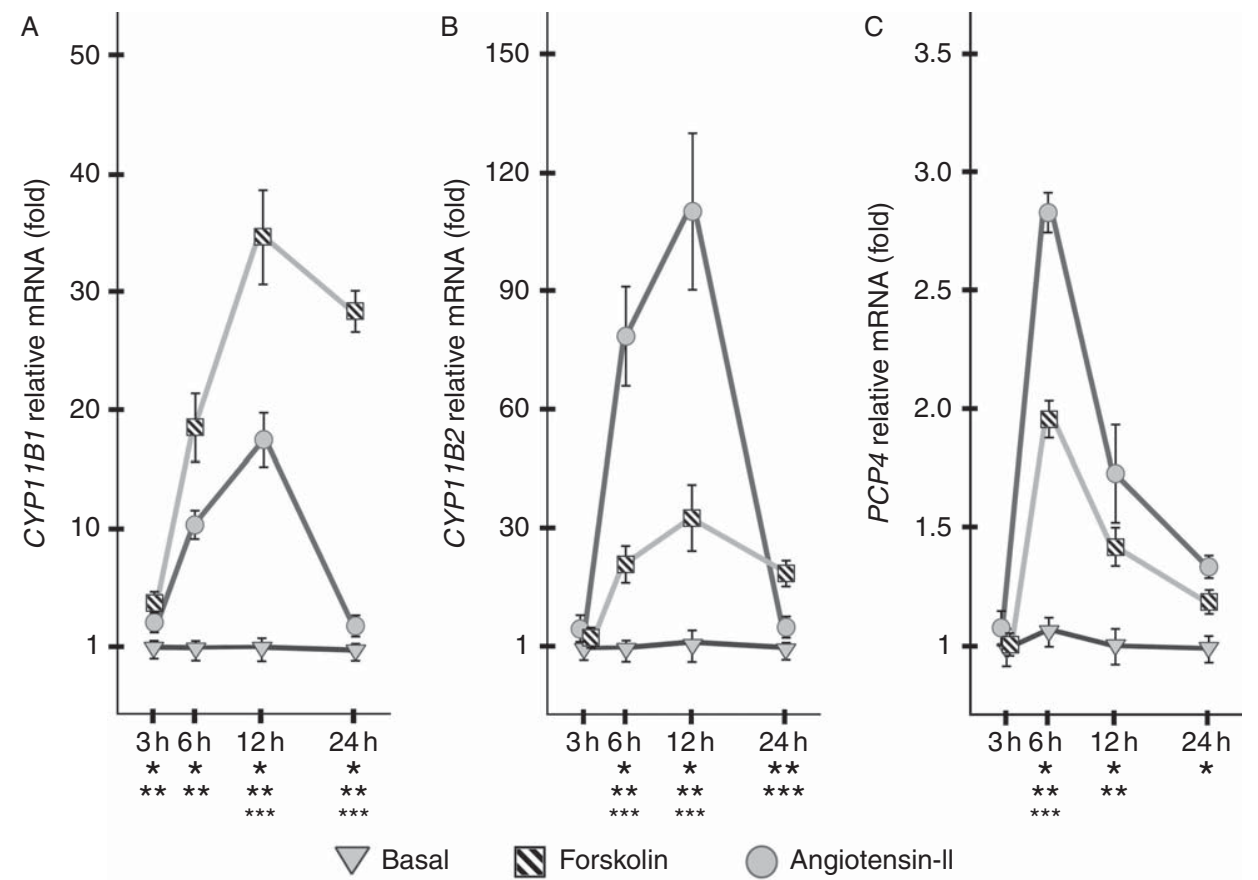

Figure 3

PCP4, CYP11B2, and CYP11B1 drug treatment time course in H295R cells. (A) CYP11B1 mRNA levels after treatment with angiotensin-II (Ang-II) and forskolin in a time-dependent manner. (B) CYP11B2 mRNA levels after
() 2014 Society for Endocrinology Printed in Great Britain treatment with Ang-II and forskolin. (C) PCP4 mRNA levels after treatment with Ang-II and forskolin. * $P<0.01$ (Ang-II vs basal); $* * P<0.01$ (forskolin vs basal); and $* * * P<0.01$ (Ang-Il vs forskolin). 
adrenocortical layers $(P<0.001)$. The semi-quantitative evaluation of cytoplasm immunoreactivity also revealed a higher number of PCP4 positive cells in the ZG of NA and IHA compared with the other zones $(P<0.001)$. The immunoreactivity of PCP4 in nuclei and cytoplasm was significantly higher in APA compared with CPA $(P<0.001$; Fig. 1C and D).

\section{QPCR analysis of APA samples}

When the qPCR results of PCP4, CYP11B1, and CYP11B2 mRNA levels in APA cases were analyzed with polynomial regression, a significantly positive correlation was detected between PCP4 and CYP11B2 $(P<0.0001 ; R>0.6$ : Fig. $2 \mathrm{~A})$, although not between PCP4 and CYP11B1 (Fig. 2B). Also, no significant correlation was detected between CYP11B2 and CYP11B1 (Fig. 2C). KCNJ5 mutations were detected in 28 of the 45 APA cases (62.2\%), and the data obtained from the clinical records of the 45 APA patients and the respective statistical correlations to KCNJ5 mutations are summarized in the Supplementary Table 1, see section on supplementary data given at the end of this article. Both PCP4 $(P=0.005)$ and CYP11B2 $(P<0.005)$ were significantly higher in KCNJ5 mutated cases, while no statistical significance of CYP11B1 mRNA levels between mutated and WT APA cases (Fig. 2D, E and F).

\section{Stimulation of H295R cells by Ang-II and forskolin}

Results of the time course of H295R cells following the treatment with Ang-II and forskolin are summarized in Fig. 3. The mRNA levels of CYP11B1 and CYP11B2 reached a peak at $12 \mathrm{~h}$, after both Ang-II and forskolin treatments (Fig. $3 \mathrm{~A}$ and B respectively), but $P C P 4$ mRNA levels peaked at $6 \mathrm{~h}$ of treatment under the same conditions (Fig. 3C). With Ang-II, PCP4 mRNA levels increased up to threefold relative to basal levels (mean \pm 0.4 s.D.), while with forskolin, PCP4 levels increased up to twofold at its peak (mean \pm 0.3 s.D.). The detection of maximum levels of PCP4 mRNA at the $6 \mathrm{~h}$ time point coincided with the elevation period of CYP11B1 and CYP11B2 mRNA levels in H295R cells.

\section{Transient transfection and luciferase assays}

Results of luciferase assays were summarized in Fig. 4. The transient transfection with PCP4 DNA vector produced significant rise of CYP11B2-LUC in PCP4-transfected H295R when Ang-II was added to cell media, compared with cells transfected with control vector $(P<0.0001)$.

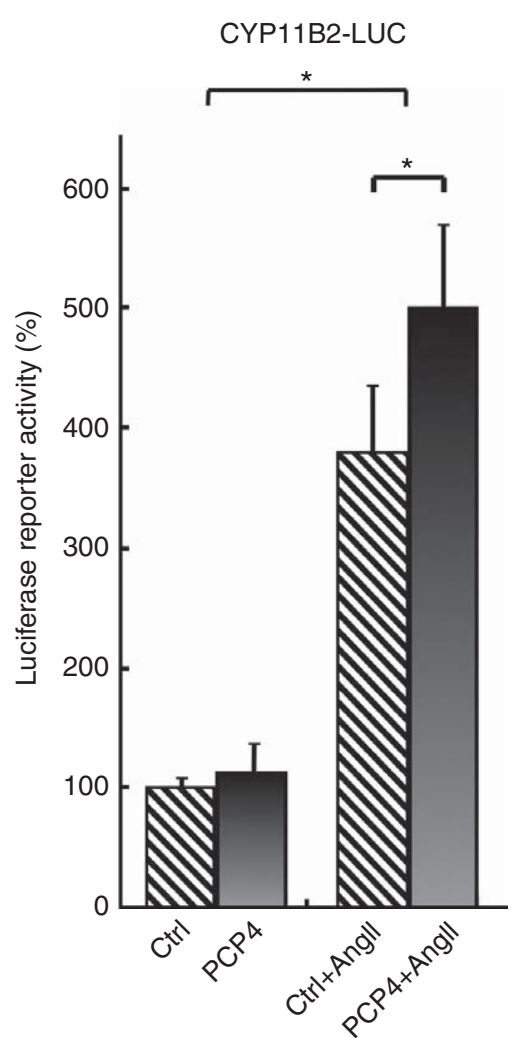

Figure 4

PCP4 transient DNA transfection and luciferase assays. Following the transient transfection with PCP4 DNA vector, CYP11B2 luciferase (CYP11B2LUC) assays were performed. When angiotensin-II (Ang-II) was added to cell media, a significant increment in CYP11B2-LUC was detected in PCP4-transfected H295R cells than empty vector cells (Ctrl). However, without Ang-II treatment, no statistically significant differences were detected, $* P<0.0001$.

Transient siRNA transfection, plasmid DNA, western blotting, and ELISA

Results of the siRNA transfection of H295R cells and subsequent western blotting and ELISA are summarized in Fig. 5. A mean of $90 \%$ knockdown of PCP4 mRNA levels $(P<0.0001$; NC $100 \% \pm 13$ s.D.; PCP4 siRNA 10\% \pm 4 s.D.; Fig. 5A) and a mean of 70\% decrement in PCP4 protein levels $(P=0.031$; NC $100 \% \pm 36$ s.D.; PCP4 siRNA $30 \% \pm 7$ s.D.; Fig. 5B) were detected in three independent experiments. Following the incubation with Ang-II for $12 \mathrm{~h}$, the PCP4 siRNA-transfected H295R cells demonstrated $\sim 30 \%$ less CYP11B2 mRNA (NC 100\% \pm 30 s.D.; PCP4 siRNA 70\% \pm 13 S.D.) than those transfected with NC siRNA $(P=0.012)$ (Fig. 5C). However, no statistical significance was detected in CYP11B1 mRNA levels between PCP4 and NC siRNAtransfected H295R cells (Fig. 5D). When cell culture media were analyzed through ELISA, a significant decrease in aldosterone production levels was detected in PCP4 siRNA

Published by Bioscientifica Ltd 
A

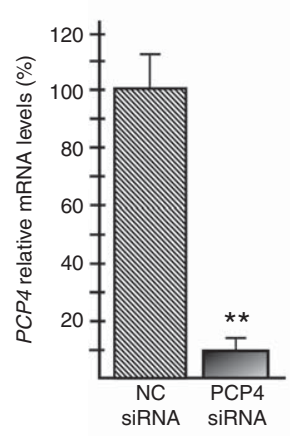

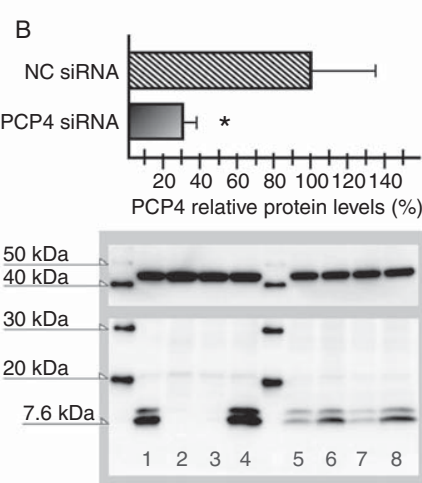

C

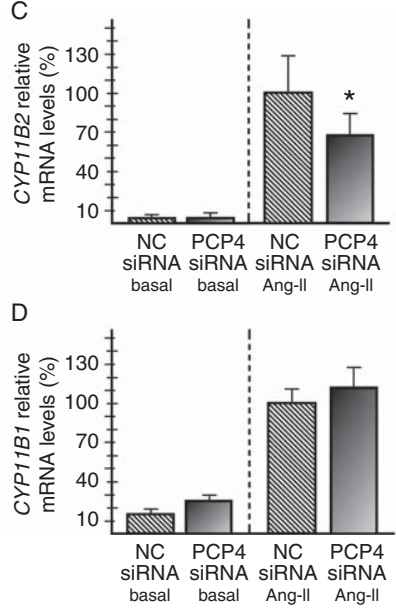

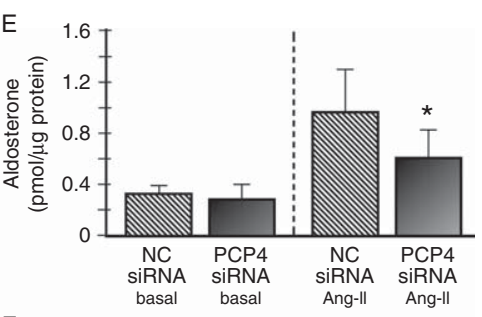

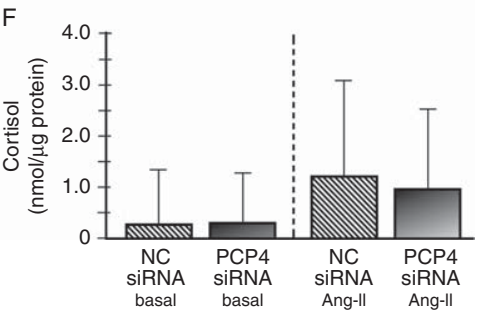

\section{Figure 5}

Transient PCP4 siRNA transfection. (A) Forty-eight hours after transfection with PCP4 siRNA, the mRNA levels of PCP4 in H295R cells decreased by $90 \%$ compared with negative control (NC) siRNA (mean, NC $100 \% \pm 13$; PCP4 siRNA $10 \% \pm 4$ s.D.; ${ }^{* * P}<0.0001$ ). (B) Immunoblotting analysis revealed a mean of $70 \%$ decrement in PCP4 protein levels (NC 100\% \pm 36 ; PCP4 siRNA $30 \% \pm 7$ s.D.; $* P<0.05$ ); the bands between 40 and $50 \mathrm{kDa}$ represent $\beta$-actin, while the bands below $20 \mathrm{kDa}$ in the expected band-size of $7.6 \mathrm{kDa}$ represent PCP4, as follows: (1) and (4) MCF7 transfected with PCP4 plasmid DNA (positive controls), (2) and (3) MCF7 transfected with empty vector, (5) and (7) H295R cells transfected with PCP4 siRNA, (6) and (8) H295R cells transfected with NC siRNA. (C) CYP11B2 mRNA levels $60 \mathrm{~h}$ after transfection: two groups of cells were submitted to angiotensin-II (Ang-II) treatment for

transfected cells treated with Ang-II $(P=0.011)$ compared with NC siRNA transfected cells treated with Ang-II (Fig. 5E); however, no statistical significance was detected between the basal, non-treated samples. In addition, no significant changes could be detected in cortisol levels between cells transfected with PCP4 siRNA and NC siRNA, either in Ang-II treated or non-treated samples (Fig. 5F).

\section{Discussion}

Results of this study demonstrated high expression levels of PCP4 protein in normal, hyperplastic, and neoplastic aldosterone-producing adrenocortical cells and tissues. Previous studies suggest a role for $\mathrm{Ca}^{2+}$ and $\mathrm{CaM}$ in aldosterone synthesis; however, the detailed intracellular mechanisms of aldosterone production still remain to be clarified (Kotchen et al. 1977, Fakunding et al. 1979, Kojima et al. 1985, Mantero et al. 1986, Kramer 1988, Laird et al. 1991, Ganguly et al. 1995, Pezzi et al. 1997, Condon et al. 2002, Nogueira et al. 2007, Romero et al. 2007, Nogueira \& Rainey 2010, Choi et al. 2011, Uruno et al. 2011, Zennaro \& Jeunemaitre 2011). Results of our present in vitro study revealed an increment in CYP11B2 mRNA levels after $6 \mathrm{~h}$ of Ang-II treatment, with a peak at the $12 \mathrm{~h}$ time point, as
$12 \mathrm{~h}$ (NC siRNA and PCP4 siRNA) while two groups remained as basal controls (no drug treatment); the comparison of Ang-II treated cells reveals a decrement in CYP11B2 mRNA levels in PCP4 siRNA-treated cells (mean 30\%; NC $100 \% \pm 30 ;$ PCP4 siRNA $70 \% \pm 13$ s.D.; $* P=0.012$ ). (D) CYP11B1 mRNA levels $60 \mathrm{~h}$ after transfection: no statistical significance could be detected between PCP4 and NC siRNA treated cells. (E) Aldosterone levels were significantly lower in PCP4 siRNA transfected cells after $48 \mathrm{~h}$ of Ang-II, compared with NC siRNA cells treated at the same conditions ( ${ }^{*} P=0.011$ ); however, there were no statistical significant differences between the basal, non-treated samples. (F) There were no statistically significant differences in cortisol levels between cells transfected with PCP4 siRNA and NC siRNA, either in Ang-II treated or non-treated samples.

previously reported (Romero et al. 2004, Xing et al. 2012). We detected the highest mRNA levels of PCP4 after $6 \mathrm{~h}$ of Ang-II and forskolin treatments in H295R cells, which coincides with the rising period of CYP11B2 in the time course experiments. As reported, the $\mathrm{Ca}^{2+} / \mathrm{CaM}$ pathway is suggested to be related to the Ang-II receptor and aldosterone production in adrenocortical cells. Therefore, we hypothesized that PCP4 is regulated by Ang-II as part of the $\mathrm{Ca}^{2+} / \mathrm{CaM}$ pathway.

In order to prove this hypothesis, we first performed luciferase assays following the transient transfection of PCP4. As our results demonstrate, the CYP11B2 luciferase was up-regulated in PCP4 transfected cells compared with controls. Then, in order to further confirm the evidence and explore whether PCP4 does serve as a key protein in aldosterone-producing pathways, we performed siRNA experiments. After $60 \mathrm{~h}$ of transient knockdown of PCP4 and $12 \mathrm{~h}$ of Ang-II treatment of H295R cells, there was a significant decrease in CYP11B2 mRNA levels compared with controls, which, together with the time course and luciferase assays data, indicated the regulation of CYP11B2 by PCP4. The lack of significant changes in the mRNA levels of CYP11B1 also indicated a specific correlation of PCP4 with the aldosterone-producing pathways in adrenocortical cells.

Published by Bioscientifica Ltd. 
We then evaluated the aldosterone production of H295R cells, and confirmed that while aldosterone production significantly decreased in PCP4 siRNA-transfected cells, cortisol production remained the same. Therefore, the results of our in vitro studies indicated that PCP4 is actually involved in the regulation of CYP11B2 and aldosterone production in human adrenocortical cells.

As a complement to in vitro data, and in order to further clarify the role of PCP4 in human adrenocortical tissues, we evaluated NA, IHA, APA, and CPA cases. The quantification of nuclear and cytoplasmic PCP4 revealed that this protein correlates with the phenotypes of aldosterone-producing cells, and our analysis suggests that PCP4 can work in conjunction with CaM in order to activate the CREB transcription factor (Deisseroth et al. 1998, Thorogate \& Török 2004). In addition, when analyzed in several APA tissue samples, the mRNA levels of PCP4 were significantly correlated with those of CYP11B2 but not with CYP11B1, which was also consistent with our in vitro results.

In this study, we attempted to clarify the mechanisms by which PCP4 could act in the aldosterone production pathway in vivo. The actions of PCP4 on $\mathrm{CaM}$ and intracellular $\mathrm{Ca}^{2+}$ homeostasis have been well studied in mammalian CNS tissues, and we hypothesized that similar mechanisms might function in human adrenal cortex (Johanson et al. 2000, Putkey et al. 2003, Kleerekoper \& Putkey 2009). The somatic mutations in the amino acids G151 and L168 of the KCNJ5 potassium $\left(\mathrm{K}^{+}\right)$channels have been reported to produce the loss of ion selectivity by the cellular membrane, and hyper-activation of voltagegated $\mathrm{Ca}^{2+}$ channels, resulting in elevation of the intracellular levels of $\mathrm{Ca}^{2+}$ in APA (Choi et al. 2011, Zennaro \& Jeunemaitre 2011), and we demonstrate that these KCNJ5 mutations are significantly correlated with the expression status of both CYP11B2 and PCP4 in APA, but not with the status of CYP11B1. In addition, our results demonstrate that KCNJ5 mutations are significantly correlated with plasmatic aldosterone concentration levels in APA patients, which suggests an indirect correlation between PCP4 and aldosterone levels in vivo.

The elevation of intracellular $\mathrm{Ca}^{2+}$ in conjunction with mutations in KCNJ5 could result in a hyperactivity of PCP4, reflected as the up-regulation of its intracellular levels in APA. However, despite the lack of KCNJ5 mutations, some APA and the ZG of NA and IHA do show higher levels of PCP4 than the adrenocortical ZF or ZR. A reason for that may be explained by the generation of spontaneous membrane potential oscillations of low periodicity by the adrenocortical ZG cells, providing a platform for the production of a recurrent $\mathrm{Ca}^{2+}$ channels signal that can be controlled by Ang-II and extracellular $\mathrm{K}^{+}$(Hu et al. 2012), but further investigations are required for clarification.

In summary, PCP4 is considered as a regulator of aldosterone synthesis, and its inhibition could suppress hyperplastic and neoplastic aldosterone production in human adrenocortical tissues.

\section{Supplementary data}

This is linked to the online version of the paper at http://dx.doi.org/10.1530/ JME-13-0248.

\section{Declaration of interest}

The authors declare that there is no conflict of interest that could be perceived as prejudicing the impartiality of the research reported.

\section{Funding}

This work was partly supported by the Takeda Science Foundation. The first author (S J A F) received scholarship support from the Ministry of Education, Culture, Sports, Science and Technology of Japan (MEXT).

\section{Author contribution statement}

$S J A F$ and $Y N$ were responsible for the design of the study, of which $S$ J A F provided the details and performed the experiments, in part or totality. Y O was partly involved in the study design and played a role in qPCR experiments. $\mathrm{K} \mathrm{K}$ was partly involved in the study design and was responsible for part of the immunohistochemical analysis. $\mathrm{K} \mathrm{K}$ was responsible for the ELISA analysis set up and performance. $Y O$ was responsible for vector DNA and qPCR primer design. $\mathrm{K}$ I was responsible for the histotechnical procedures and human tissue management. K T performed the radiological diagnosis of the adrenocortical tumors used in the study. A S performed the cell transfections and the luciferase assays. $\mathrm{N} \mathrm{H}$ provided insights on adrenocortical physiology and intracellular pathways. W E R, F S, and H S provided expertise and valuable opinion on the study design and interpretation of the results.

\section{References}

Bird IM, Mason JI \& Rainey WE 1995 Hormonal regulation of angiotensin II type 1 receptor expression and AT1-R mRNA levels in human adrenocortical cells. Endocrine Research 21 169-182. (doi:10.3109/ 07435809509030432)

Choi M, Scholl UI, Yue P, Bjorklund P, Zhao B, Nelson-Williams C, Ji W, Cho Y, Patel A, Men CJ et al. $2011 \mathrm{~K}^{+}$channel mutations in adrenal aldosterone-producing adenomas and hereditary hypertension. Science 331 768-772. (doi:10.1126/science.1198785)

Condon JC, Pezzi V, Drummond BM, Yin S \& Rainey WE 2002 Calmodulindependent kinase I regulates adrenal cell expression of aldosterone synthase. Endocrinology 143 3651-3657. (doi:10.1210/en.2001-211359)

Deisseroth K, Heist EK \& Tsien RW 1998 Translocation of calmodulin to the nucleus supports CREB phosphorylation in hippocampal neurons. Nature 392 198-202. (doi:10.1038/32448) http://jme.endocrinology-journals.org DOI: 10.1530/JME-13-0248
C 2014 Society for Endocrinology Printed in Great Britain
Published by Bioscientifica Ltd 
Erhardt JA, Legos JJ, Johanson RA, Slemmon JR \& Wang X 2000 Expression of PEP-19 inhibits apoptosis in PC12 cells. Neuroreport 11 3719-3723. (doi:10.1097/00001756-200011270-00026)

Fakunding JL, Chow R \& Catt KJ 1979 The role of calcium in the stimulation of aldosterone production by adrenocorticotropin, angiotensin II, and potassium in isolated glomerulosa cells. Endocrinology 105 327-333. (doi:10.1210/endo-105-2-327)

Felizola SJA, Nakamura Y, Arata Y, Ise K, Satoh F, Rainey WE, Midorikawa S, Suzuki S \& Sasano H 2013a Metallothionein-3 (MT-3) in the human adrenal cortex and its disorders. Endocrine Pathology [in press]. (doi:10.1007/s12022-013-9280-9)

Felizola SJA, Nakamura Y, Hui XG, Satoh F, Morimoto R, McNamara KM, Midorikawa S, Suzuki S, Rainey WE \& Sasano H 2013b Estrogen-related receptor $\alpha$ in normal adrenal cortex and adrenocortical tumors: involvement in development and oncogenesis. Molecular and Cellular Endocrinology 365 207-211. (doi:10.1016/j.mce.2012.10.020)

Felizola SJA, Nakamura Y, Satoh F, Morimoto R, Kikuchi K, Nakamura T, Hozawa A, Wang L, Onodera Y, Ise K et al. 2014 Glutamate receptors and the regulation of steroidogenesis in the human adrenal gland: the metabotropic pathway. Molecular and Cellular Endocrinology 382 170-177. (doi:10.1016/j.mce.2013.09.025)

Ganguly A, Li L \& Haxton M 1995 Inhibition of angiotensin II- and potassium-mediated aldosterone secretion by KN-62 suggests involvement of $\mathrm{Ca}(2+)$-calmodulin dependent protein kinase II in aldosterone secretion. Biochemical and Biophysical Research Communications 209 916-920. (doi:10.1006/bbrc.1995.1585)

Hu C, Rusin CG, Tan Z, Guagliardo NA \& Barrett PQ 2012 Zona glomerulosa cells of the mouse adrenal cortex are intrinsic electrical oscillators. Journal of Clinical Investigation 122 2046-2053. (doi:10.1172/JCI61996)

Hui XG, Akahira J, Suzuki T, Nio M, Nakamura Y, Suzuki H, Rainey WE \& Sasano H 2009 Development of the human adrenal zona reticularis: morphometric and immunohistochemical studies from birth to adolescence. Journal of Endocrinology 203 241-252. (doi:10.1677/JOE-09-0127)

Johanson RA, Sarau HM, Foley JJ \& Slemmon JR 2000 Calmodulin-binding peptide PEP-19 modulates activation of calmodulin kinase II in situ. Journal of Neuroscience $202860-2866$.

Kleerekoper QK \& Putkey JA 2009 PEP-19, an intrinsically disordered regulator of calmodulin signaling. Journal of Biological Chemistry $\mathbf{2 8 4}$ 7455-7464. (doi:10.1074/jbc.M808067200)

Kojima I, Kojima K \& Rasmussen H 1985 Role of calcium and cAMP in the action of adrenocorticotropin on aldosterone secretion. Journal of Biological Chemistry $2604248-4256$.

Kotchen TA, Galla JH \& Luke RG 1977 Effects of calcium on renin and aldosterone in the rat. American Journal of Physiology 232 E388-E393.

Kramer RE 1988 Angiotensin II causes sustained elevations in cytosolic calcium in glomerulosa cells. American Journal of Physiology 255 E338-E346.

Lai TH, King JA, Shih IM, Vlahos NF \& Zhao Y 2007 Immunological localization of syndecan-1 in human endometrium throughout the menstrual cycle. Fertility and Sterility 87 121-126. (doi:10.1016/ j.fertnstert.2006.06.042)

Laird SM, Hinson JP, Vinson GP, Mallick N, Kapas S \& Teja R 1991 Control of steroidogenesis by the calcium messenger system in human adrenocortical cells. Journal of Molecular Endocrinology 6 45-51. (doi:10.1677/jme.0.0060045)

Mantero F, Rocco S, Opocher G, Boscaro M, Fallo F \& D'Agostino D 1986 Osterone, calcium, and hypertension. American Journal of Nephrology 6 33-39. (doi:10.1159/000167213)

Nakamura Y, Satoh F, Morimoto R, Kudo M, Takase K, Gomez-Sanchez CE, Honma S, Okuyama M, Yamashita K, Rainey WE et al. 2011 18-Oxocortisol measurement in adrenal vein sampling as a biomarker for subclassifying primary aldosteronism. Journal of Clinical Endocrinology and Metabolism 96 E1272-E1278. (doi:10.1210/jc.2010-2785)

Nogueira EF \& Rainey WE 2010 Regulation of aldosterone synthase by activator transcription factor/cAMP response element-binding protein family members. Endocrinology 151 1060-1070. (doi:10.1210/en.2009-0977)

Nogueira EF, Vargas CA, Otis M, Gallo-Payet N, Bollag WB \& Rainey WE 2007 Angiotensin-II acute regulation of rapid response genes in human, bovine, and rat adrenocortical cells. Journal of Molecular Endocrinology 39 365-374. (doi:10.1677/JME-07-0094)

Pezzi V, Clyne CD, Ando S, Mathis JM \& Rainey WE 1997 Ca(2+)-regulated expression of aldosterone synthase is mediated by calmodulin and calmodulin-dependent protein kinases. Endocrinology 138 835-838. (doi:10.1210/endo.138.2.5032)

Putkey JA, Kleerekoper Q, Gaertner TR \& Waxham MN 2003 A new role for IQ motif proteins in regulating calmodulin function. Journal of Biological Chemistry 278 49667-49670. (doi:10.1074/jbc.C300372200)

Romero DG, Plonczynski M, Vergara GR, Gomez-Sanchez EP \& GomezSanchez CE 2004 Angiotensin II early regulated genes in H295R human adrenocortical cells. Physiological Genomics 19 106-116. (doi:10.1152/physiolgenomics.00097.2004)

Romero DG, Plonczynski MW, Gomez-Sanchez EP, Yanes LL \& GomezSanchez CE 2007 RGS2 is regulated by angiotensin II and functions as a negative feedback of aldosterone production in H295R human adrenocortical cells. Endocrinology 147 3889-3897. (doi:10.1210/en.2005-1532)

Sangameswaran L, Hempstead J \& Morgan JI 1989 Molecular cloning of a neuron-specific transcript and its regulation during normal and aberrant cerebellar development. PNAS 86 5651-5655. (doi:10.1073/ pnas.86.14.5651)

Satoh F, Abe T, Tanemoto M, Nakamura M, Abe M, Uruno A, Morimoto R, Sato A, Takase K, Ishidoya S et al. 2007 Localization of aldosteroneproducing adrenocortical adenomas: significance of adrenal venous sampling. Hypertension Research 30 1083-1095. (doi:10.1291/hypres.30. 1083)

Slemmon JR, Feng B \& Erhardt JA 2000 Small proteins that modulate calmodulin-dependent signal transduction: effects of PEP-19, neuromodulin, and neurogranin on enzyme activation and cellular homeostasis. Molecular Neurobiology 22 99-113. (doi:10.1385/MN:22:1-3:099)

Sukor N, Gordon RD, Ku YK, Jones M \& Stowasser M 2009 Role of unilateral adrenalectomy in bilateral primary aldosteronism: a 22-year single center experience. Journal of Clinical Endocrinology and Metabolism 94 2437-2445. (doi:10.1210/jc.2008-2803)

Thorogate R \& Török K $2004 \mathrm{Ca}^{2+}$-dependent and -independent mechanisms of calmodulin nuclear translocation. Journal of Cell Science 117 5923-5936. (doi:10.1242/jcs.01510)

Uruno A, Matsuda K, Noguchi N, Yoshikawa T, Kudo M, Satoh F, Rainey WE, Hui XG, Akahira J, Nakamura Y etal. 2011 Peroxisome proliferator-activated receptor-\{r\} suppresses CYP11B2 expression and aldosterone production. Journal of Molecular Endocrinology 46 37-49. (doi:10.1677/JME-10-0088)

Wang T, Satoh F, Morimoto R, Nakamura Y, Sasano H, Auchus RJ, Edwards MA \& Rainey WE 2011 Gene expression profiles in aldosterone-producing adenomas and adjacent adrenal glands. European Journal of Endocrinology 164 613-619. (doi:10.1530/EJE-10-1085)

Wei P, Blundon JA, Rong Y, Zakharenko SS \& Morgan JI 2011 Impaired locomotor learning and altered cerebellar synaptic plasticity in pep-19/pcp4-null mice. Molecular and Cellular Biology 31 2838-2844. (doi:10.1128/MCB.05208-11)

Xing Y, Rainey WE, Apolzan JW, Francone OL, Harris RB \& Bollag WB 2012 Adrenal cell aldosterone production is stimulated by very-low-density lipoprotein (VLDL). Endocrinology 153 721-731. (doi:10.1210/en.2011-1752)

Zennaro MC \& Jeunemaitre X 2011 Mutations in KCNJ5 gene cause hyperaldosteronism. Circulation Research 108 1417-1418. (doi:10.1161/ RES.0b013e318224a359)

Received in final form 3 January 2014

Accepted 8 January 2014

Accepted Preprint published online 8 January 2014 